\title{
Plasma Glucose Measurement
}

National Cancer Institute

\section{Source}

National Cancer Institute. Plasma Glucose Measurement. NCI Thesaurus. Code C41376.

Glucose Plasma Concentration (GPC) measurement is an essential diagnostic modality for different types of carbohydrate metabolism derangements including diabetes mellitus. The disordered carbohydrate metabolism that underlies diabetes manifests as hyperglycemia. Plasma glucose concentrations in healthy individuals vary with age. Normal fasting plasma glucose intervals (in the morning after an overnight fast) in children are 3.3 - $5.6 \mathrm{mmol} / \mathrm{L}$ (60-100 $\mathrm{mg} / \mathrm{dL}) ;$ adult range - 4.1 $5.9 \mathrm{mmol} / \mathrm{L}$ (74-106 $\mathrm{mg} / \mathrm{dL})$. GPCs are approximately $11 \%$ higher than whole blood if the hematocrit is normal. Glucose concentrations in heparinized plasma are reported to be 5\% lower than in serum. 